\title{
BMJ Open Sex-specific temporal trends in ambulatory heart failure incidence, mortality and hospitalisation in Ontario, Canada from 1994 to 2013: a population- based cohort study
}

\author{
Louise Y Sun (D , ${ }^{1,2,3}$ Lisa M Mielniczuk, ${ }^{4}$ Peter P Liu, ${ }^{4}$ Rob S Beanlands, ${ }^{4}$ \\ Sharon Chih, ${ }^{4}$ Ross Davies, ${ }^{4}$ Thais Coutinho, ${ }^{4,5}$ Douglas S Lee, ${ }^{2,6}$ Peter C Austin, ${ }^{2}$ \\ Anan Bader Eddeen, ${ }^{2}$ Jack V Tu ${ }^{2,7}$
}

To cite: Sun LY, Mielniczuk LM, Liu PP, et al. Sex-specific temporal trends in ambulatory heart failure incidence, mortality and hospitalisation in Ontario, Canada from 1994 to 2013: a population-based cohort study. BMJ Open 2020;10:e044126. doi:10.1136/ bmjopen-2020-044126

- Prepublication history and additional material for this paper are available online. To view these files, please visit the journal online (http://dx.doi. org/10.1136/bmjopen-2020044126).

Dr. Tu is deceased

LYS and LMM are joint first authors.

Received 24 August 2020 Revised 07 October 2020 Accepted 06 November 2020

Check for updates

(c) Author(s) (or their employer(s)) 2020. Re-use permitted under CC BY-NC. No commercial re-use. See rights and permissions. Published by BMJ.

For numbered affiliations see end of article.

Correspondence to

Dr Louise Y Sun;

Isun@ottawaheart.ca

\section{ABSTRACT}

Objectives To examine the temporal trends in mortality and heart failure (HF) hospitalisation in ambulatory patients following a new diagnosis of HF.

Design Retrospective cohort study

Setting Outpatient

Participants Ontario residents who were diagnosed with HF in an outpatient setting between 1994 and 2013.

Primary and secondary outcome measures The primary outcome was all-cause mortality within 1 year of diagnosis and the secondary outcome was HF hospitalisation within 1 year. Risks of mortality and hospitalisation were calculated using the Kaplan-Meier method and the relative hazard of death was assessed using multivariable Cox proportional hazard models. Results A total of 352329 patients were studied (50\% female). During the study period, there was a greater decline in age standardised 1-year mortality rates (AMR) in men $(33 \%)$ than in women (19\%). Specifically, female AMR at 1 year was $10.4 \%(95 \% \mathrm{Cl} 9.1 \%$ to $12.0 \%)$ in 1994 and $8.5 \%$ (95\% Cl 7.5\% to 9.5\%) in 2013, and male AMR at 1 year was $12.3 \%(95 \% \mathrm{Cl} 11.1 \%$ to $13.7 \%)$ in 1994 and $8.3 \%$ (95\% Cl 7.5\% to $9.1 \%$ ) in 2013. Conversely, age standardised HF hospitalisation rates declined in men (11.4\% (95\% Cl $10.1 \%$ to $12.9 \%)$ in 1994 and $9.1 \%$ (95\% $\mathrm{Cl} 8.2 \%$ to $10.1 \%$ ) in 2013) but remained unchanged in women $(9.7 \%(95 \% \mathrm{Cl} 8.3 \%$ to $11.3 \%)$ in 1994 and $9.8 \%$ (95\% Cl 8.6\% to $11.0 \%$ ) in 2013).

Conclusion Among patients with HF over a 20-year period, there was a greater improvement in the prognosis of men compared with women. Further research should focus on the determinants of this disparity and ways to reduce this gap in outcomes.

\section{INTRODUCTION}

Heart failure (HF) is a significant cause of morbidity and mortality for both women and men. ${ }^{2}$ Despite the current era of guideline directed medical therapy, HF continues to be a leading cause of admission to hospital. It is associated with a poor
Strengths and limitations of this study

- First and largest population-based study to examine temporal, sex-specific trends in heart failure (HF) outcomes in an ambulatory setting.

- The nature of our publicly funded healthcare system allowed for analysis of all patients diagnosed with $\mathrm{HF}$ in Ontario without selection bias.

- Information on ejection fraction was not available in the databases used.

prognosis and contributes to $35 \%$ of cardiovascular mortality in women. ${ }^{3}$ Despite this, HF remains poorly understood in women, and women continue to be underrepresented in HF clinical trials. ${ }^{4}$ The underlying mechanism of HF is often different in women and men, with women suffering more often from $\mathrm{HF}$ of a hypertensive rather than ischaemic aetiology. ${ }^{56}$ Important trends in the incidence and outcomes of hospitalised HF patients have been recently published ${ }^{78}$; these studies suggest that the incidence of HF has declined in many inpatient cohorts, however, the prognosis of this disease remains poor. An in-depth understanding of the temporal trends in HF incidence and outcomes is also needed in the ambulatory setting, where the majority of HF cases are diagnosed and managed. Also, given the sex differences in comorbidities and outcomes in HF, it is not known if these temporal changes are modified by sex. We, therefore, examined the sex differences in HF comorbidities, incidence, mortality and hospitalisation in a populationbased ambulatory cohort from fiscal years 1994 to 2013. 


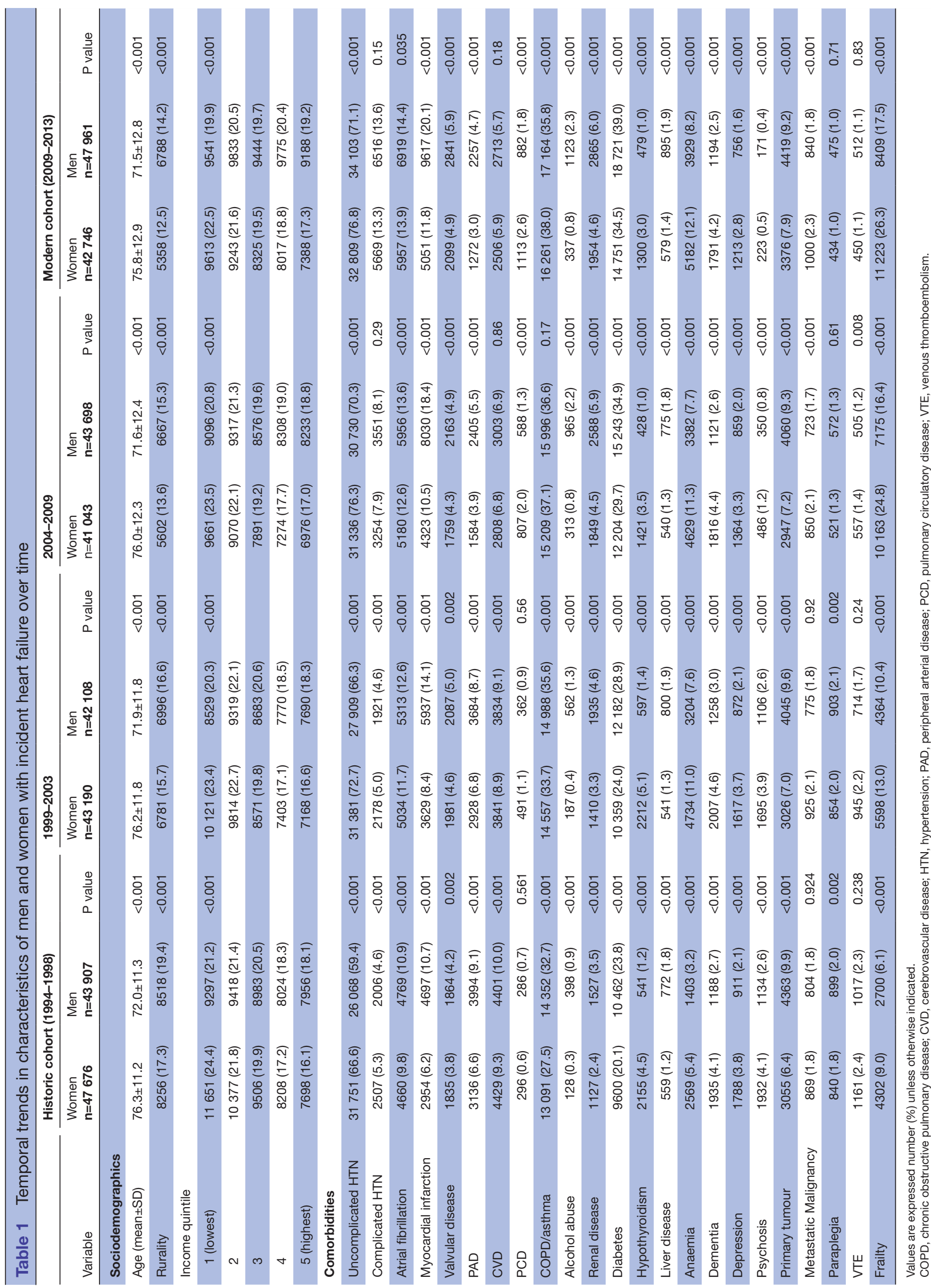




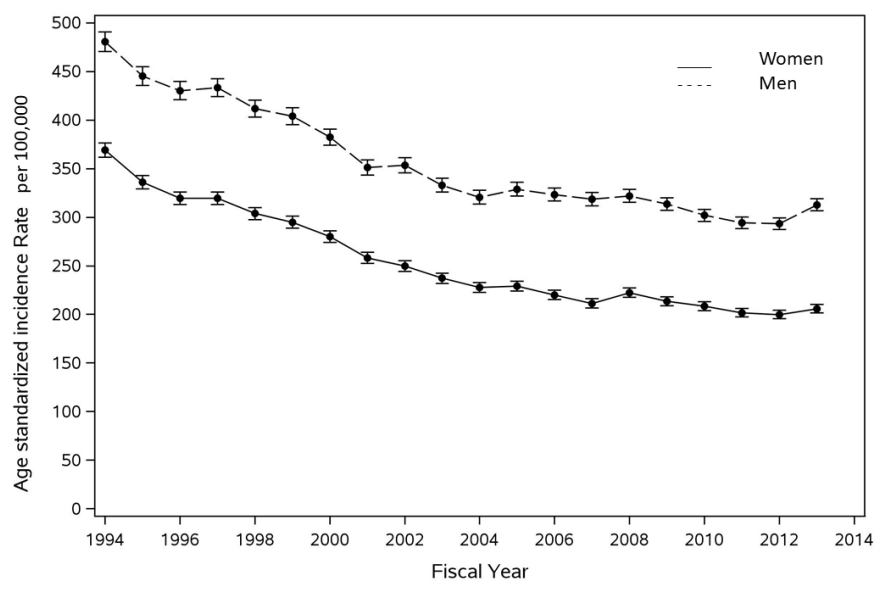

Figure 1 Sex-specific temporal trends in the incidence of heart failure in Ontario from 1 April 1994 to 31 March 2014. Incidence rates were directly standardised by age and expressed per 100000 . The solid line represents incidence trends in women. The dotted line represents incidence trends in men.

\section{METHODS}

\section{Design and study population}

We conducted a population-based, retrospective cohort study of Ontario residents who were diagnosed with HF in an outpatient setting over a 20 -year period, using linked administrative databases.

Included were adult patients $\geq 40$ years of age, who were newly diagnosed with HF in an ambulatory setting between 1 April 1994 and 31 March 2014. We excluded non-Ontario residents, those who were $\geq 105$ years of age on the date of HF diagnosis, those who were diagnosed with $\mathrm{HF}$ in an inpatient setting and in whom HF had developed as a postadmission complication. Ontario is Canada's most populous and ethnically diverse province with a public funded healthcare system that reimburses all medically necessary physician and hospital services.

\section{Patient and public involvement}

Patients and the public were not involved in the design and conception of this study. However, the results will be publicly disseminated.

\section{Data sources}

Databases were linked deterministically using unique encoded identifiers. Ambulatory incident HF cases were identified using the Institute for Clinical Evaluative Sciences Congestive HF database, based on two outpatient billing claims for $\mathrm{HF}$ within 1 year. This algorithm was validated in primary care patient records and shown to have $85 \%$ sensitivity and $97 \%$ specificity in identifying HF events. ${ }^{9}$ The congestive HF database allowed us to study a validated cohort of HF patients with consistent entry criteria over time. Our analyses were conducted by linking the Congestive HF database with the Registered Persons Database, which contains demographic and vital statistics information, the Canadian Institute for Health Information Discharge Abstract Database, which contains data on all hospitalisations and comorbidities, and Same Day Surgery database for comorbidities. Physician fee-forservice claims data were obtained from the Ontario Health Insurance Plan database. While lacking physiologic and laboratory measures, these databases have been validated for many outcomes, exposures and comorbidities. ${ }^{10-13}$

\section{Outcome}

The primary outcome was all-cause mortality within 1 year of HF diagnosis. Mortality was ascertained by using the Registered Persons Database. Secondary outcome was HF hospitalisation within 1 year of HF diagnosis, which was ascertained using the Discharge Abstract Database.

\section{Covariates}

Demographic variables were obtained from the Registered Persons Database. We estimated socioeconomic status based on patients' neighbourhood median income in the Canadian census, and determined rural versus urban residence using Statistics Canada definitions. ${ }^{14} \mathrm{We}$ identified hypertension, ${ }^{10}$ asthma, ${ }^{15}$ chronic obstructive pulmonary disease (COPD) ${ }^{16}$ and diabetes mellitus ${ }^{12}$ using validated algorithms applied on patient encounters within 5 years of HF diagnosis. Other comorbidities were identified using Discharge Abstract Database, Same Day Surgery and Ontario Health Insurance Plan databases based on International Classification of Diseases 10th Revision codes within 5 years of HF diagnosis, using previously described methods. ${ }^{17-29}$ Frailty was identified using the Johns Hopkins Adjusted Clinical Groups frailtydefining diagnoses indicator, which is an instrument designed and validated for research of frailty-related outcomes and resource utilisation using administrative data. $^{25} 2830-34$

\section{Statistical analysis}

Analyses were stratified by sex. Continuous variables were expressed as mean (SD) and categorical variables as number (proportion). Mortality was assessed at 1-year post-HF diagnosis. Survival time was defined as the date of HF diagnosis until date of death or last follow-up. Patients were censored when they lost possession of a valid Ontario health insurance number for two consecutive eligibility quarters (ie, have left the province of Ontario). Probability of death within given durations of follow-up were calculated using the Kaplan-Meier method, with the significance of the difference between sexes assessed using the log-rank test. We estimated the cumulative incidence of HF hospitalisations using cumulative incidence functions, which treated death as a competing risk. We constructed age standardised plots of $\mathrm{HF}$ incidence, 1-year mortality and HF hospitalisation in men and women over the 20-year period. These rates were directly standardised by age using the 1991 Canadian population aged $\geq 40$ years as the reference population.

We used linear regression with fiscal year as the independent variable to assess for temporal changes in $\mathrm{HF}$ incidence and outcomes in women and men across the 


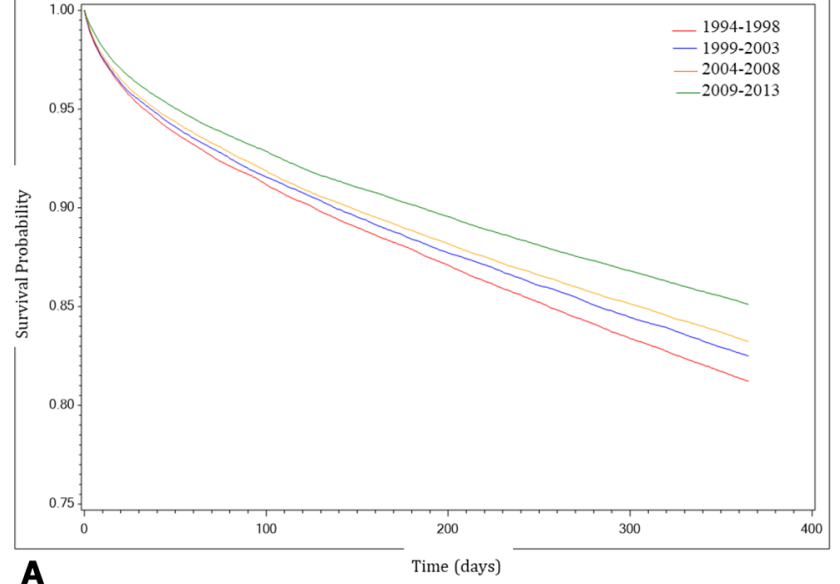

A

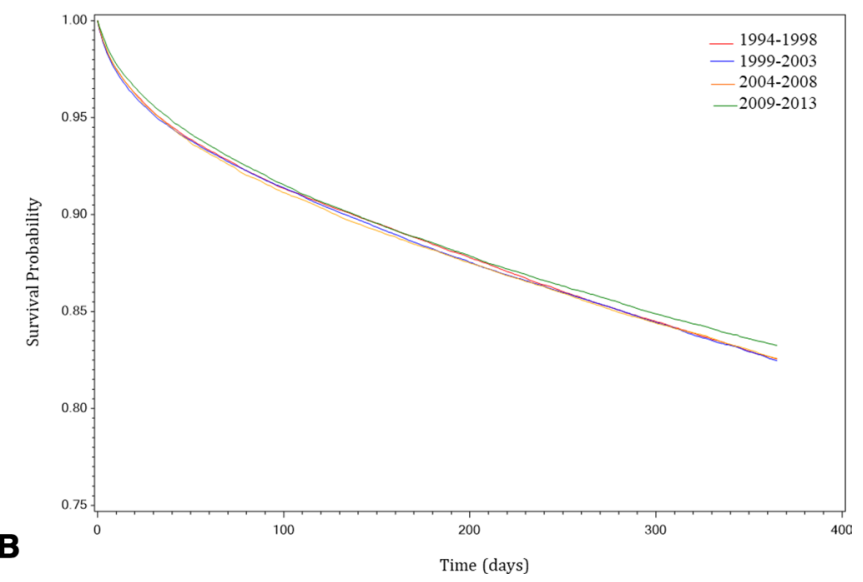

Figure 2 (A) Stacked Kaplan-Meier curves representing temporal trends in 1-year survival after heart failure diagnosis in men. The red line represents survival in the historical cohort (1994-1998). The blue line represents survival in the 1999-2003 cohort. The orange line represents survival in the 2004-2008 cohort. The green line represents survival in the modern cohort (2009-2013). (B) Stacked Kaplan-Meier curves representing temporal trends in 1-year survival after heart failure diagnosis in women. The red line represents survival in the historical cohort (1994-1998). The blue line represents survival in the 1999-2003 cohort. The orange line represents survival in the 2004-2008 cohort. The green line represents survival in the modern cohort (2009-2013).

20-year period. To examine the temporal changes in comorbidities, we divided the 20-year period into four temporal cohorts: those diagnosed with HF between 1 April 1994 and 31 March 1999 (the historical cohort), between 1 April 1999 and 31 March 2004, between 1 April 2004 and 31 March 2009 and between 1 April 2009 and 31 March 2014 (the modern cohort). The hazard of death in the historical cohort and the modern cohort were assessed using Cox proportional hazard models with and without multivariable adjustment. To justify sex-specific analyses, we also tested for the presence of any interaction between sex and each of the mortality risk factors in

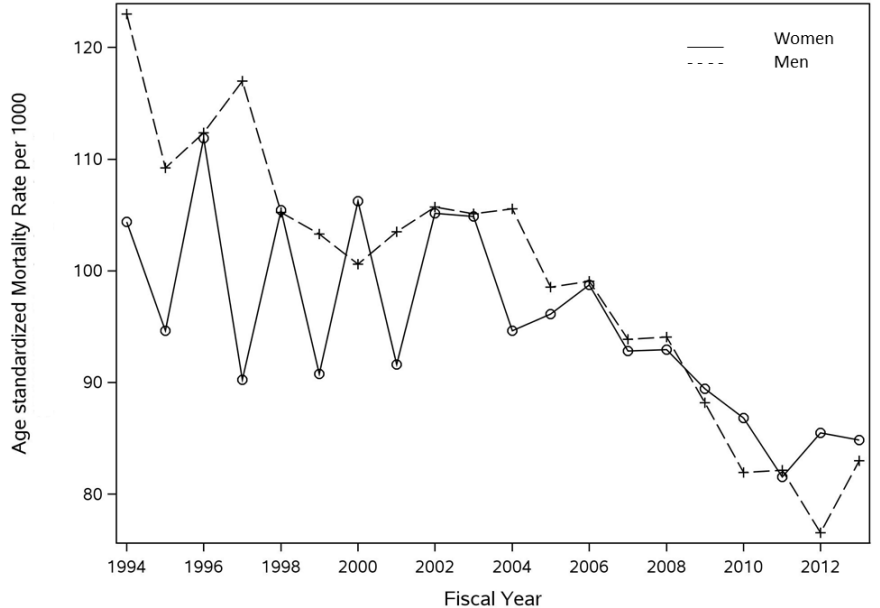

Figure 3 Sex-specific temporal trends in mortality within 1-year of ambulatory heart failure diagnosis. Mortality rates were directly standardised by age and expressed per 1000 . The solid line represents mortality trends in women. The dotted line represents mortality trends in men.

these two cohorts using multiplicative interaction terms. The measure of association was HRs with 95\% CI. Analyses were performed using SAS V.9.4 (SAS Institute), with statistical significance defined by a two-sided $\mathrm{p}<0.05$.

\section{RESULTS}

Over a 20-year period in Ontario, a total of 352329 patients were diagnosed with HF in an ambulatory setting (50\% women). There were 91583 incident HF cases in the historical cohort (52\% women) and 90707 in the modern cohort (47\% women). Throughout the study period, women with HF were more likely to be older, more frail, of lower income status, have comorbid conditions such as hypertension, hypothyroidism, anaemia, dementia and depression, but were less likely to have myocardial infarction (MI), peripheral arterial disease, diabetes and alcohol abuse compared with men (table 1). Compared with the historical cohort, modern HF patients were less likely to have peripheral and cerebral vascular disease, psychosis, paraplegia and venous thromboembolic disease; but more likely to be urban dwellers, have hypertension, atrial fibrillation, MI, valvular heart disease, pulmonary circulatory disorder, COPD/asthma, alcohol abuse, renal disease and are increasingly frail.

\section{Trends in HF incidence}

During the historical period (1994-1998), a total of 47 $676(0.36 \%)$ incident HF cases were identified in women and $43907(0.36 \%)$ in men. During the modern era (2009-2013), 42746 (0.24\%) incident cases were identified in women and 47961 (0.29\%) in men. Although the incidence of HF declined in both sexes over the 20-year period (linear regression slope, $-0.031 ; \mathrm{p}<0.0001$ in women and $-0.025 ; \mathrm{p}<0.0001$ in men), it remained higher in men than in women (figure 1). Age-standardised incidence for women decreased from 369.0 (95\% CI 361.7 to 
April 1, 1994 - March 31,1999:

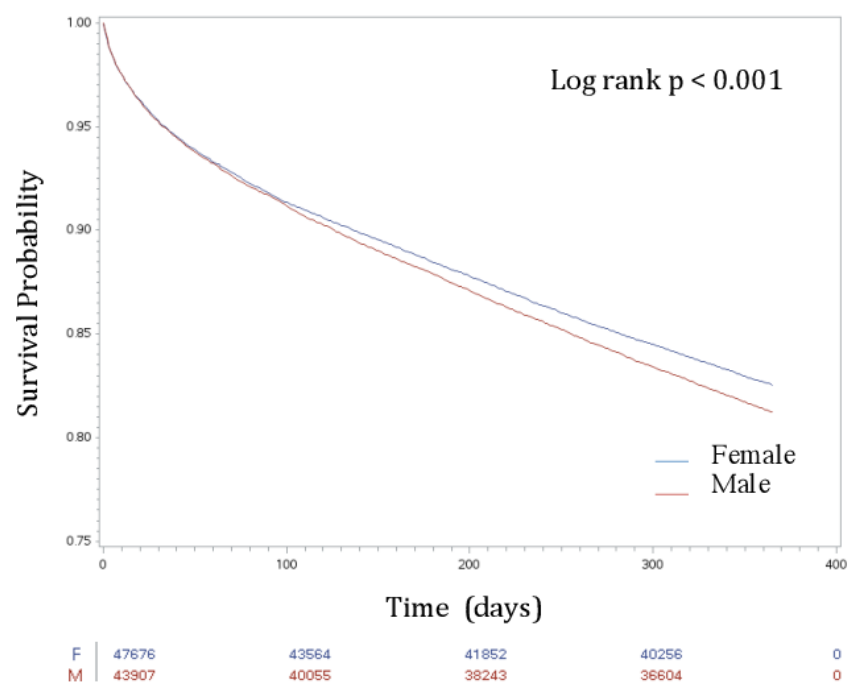

April 1, 2004 - March 31, 2009:

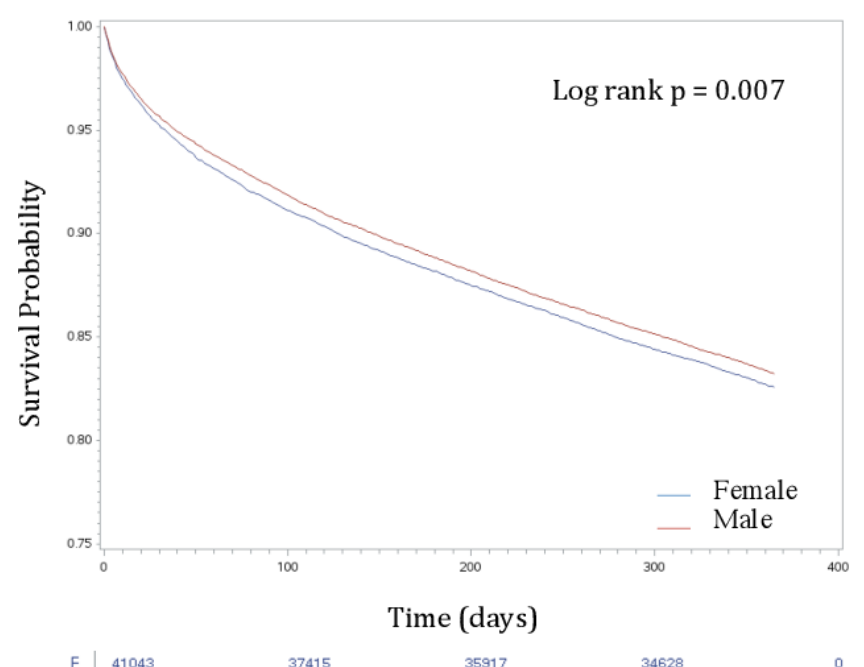

April 1, 1999 - March 31, 2004 :

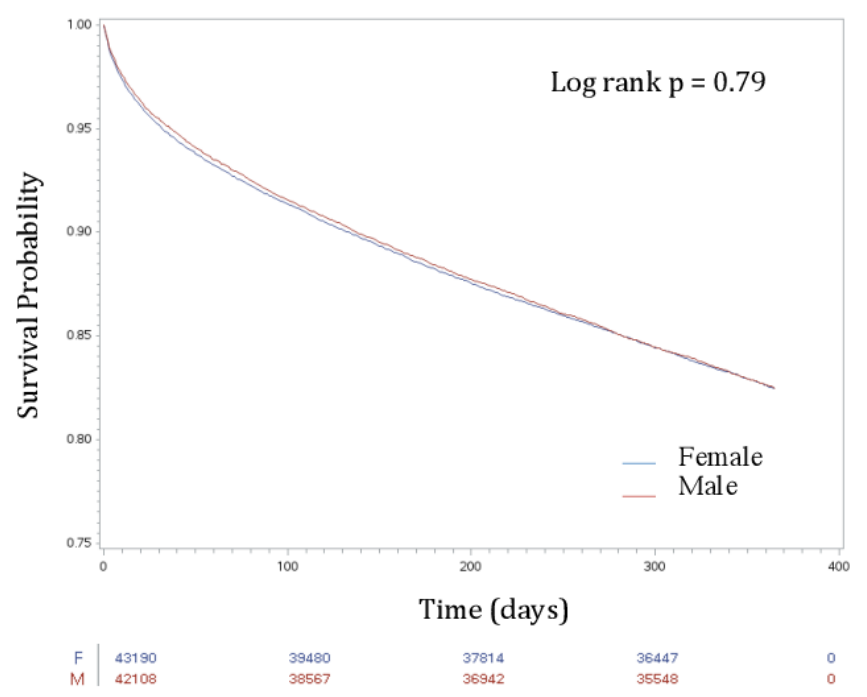

April 1, 2009 - March 31, 2014 :

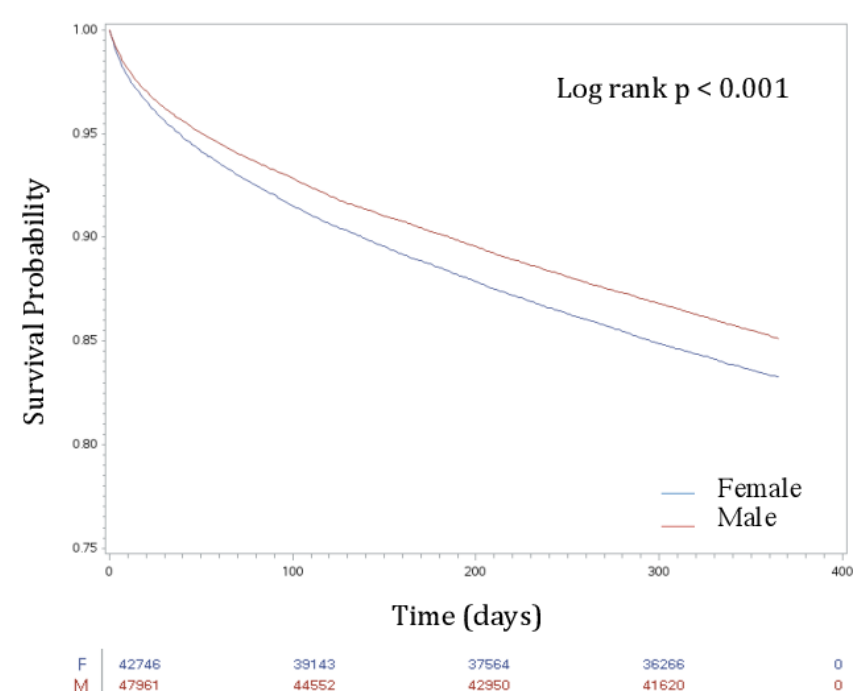

Figure 4 Kaplan-Meier curves representing temporal trends in 1-year survival after heart failure diagnosis, in each of the 5year cohorts. The red line represents survival in men. The blue line represents survival in women.

376.3) per 100000 population in 1994 to 205.8 (201.4210.3) in 2013. For men, HF incidence decreased from 480.6 (470.6-490.9) per 100000 in 1994 to 312.8 (306.8318.9 ) in 2013 (online supplemental table 1).

\section{Trends in mortality}

One-year mortality occurred in 8319 (17.5\%) women and $8238(18.8 \%)$ men during the historical period; it occurred in $7156(16.8 \%)$ women and $7138(14.9 \%)$ men during the modern period (online supplemental table 2). These survival patterns are reinforced by the Kaplan-Meier survival curves in figure 2, as well as the stacked Kaplan-Meier curves in figure 3 that demonstrate an improvement in male survival (linear regression slope, $-0.020 ; \mathrm{p}<0.0001)$ but relatively little change in female survival over time (linear regression slope, -0.010 ; $\mathrm{p}=0.001)$. Age-standardised 1-year mortality rates (AMR) also declined in both sexes but the magnitude of reduction was greater in men than in women. Men had higher AMR than women at most time points prior to 2009 (figure 4). Specifically, the female AMR was $10.4 \%(95 \%$ CI $9.1 \%$ to $12.0 \%$ ) in 1994 and $8.5 \%$ (95\% CI $7.5 \%$ to $9.5 \%$ ) in 2013, representing a $19 \%$ reduction. Conversely, male AMR was $12.3 \%$ (95\% CI $11.1 \%$ to $13.7 \%$ ) in 1994 and $8.3 \%$ (95\% CI $7.5 \%$ to $9.1 \%$ ) in 2013, representing a $33 \%$ reduction (online supplemental table 3 ).

In the unadjusted analysis, female sex was protective against 1-year mortality in the historical cohort (unadjusted HR 0.93 , $95 \%$ CI 0.90 to 0.95 ) but was associated with a higher risk of mortality (unadjusted HR 1.14, 95\% CI 1.10 to 1.18 ) in the modern cohort. Adjusted analysis 
Table 2 Evolution of multivariable risk factors of 1-year mortality over time

Adjusted HR (95\% Cl)

\begin{tabular}{|c|c|c|c|c|}
\hline Variable & 1994-1998 & 1999-2003 & $2004-2008$ & 2009-2013 \\
\hline \multicolumn{5}{|l|}{ Age category } \\
\hline 40-64 years & Reference & Reference & Reference & Reference \\
\hline $65-74$ years & 1.56 (1.47 to 1.65$)$ & 1.64 (1.53 to 1.74$)$ & $1.66(1.56$ to 1.77$)$ & 1.54 (1.44 to 1.64$)$ \\
\hline $75-84$ years & 2.26 (2.14 to 2.39$)$ & 2.36 (2.23 to 2.5$)$ & 2.48 (2.34 to 2.63$)$ & 2.58 (2.43 to 2.73 ) \\
\hline$>85$ years & 3.68 (3.48 to 3.90$)$ & 4.25 (4.00 to 4.51$)$ & 4.57 (4.31 to 4.85$)$ & 4.89 (4.62 to 5.18$)$ \\
\hline Female & 0.85 (0.82 to 0.88$)$ & 0.89 (0.86 to 0.92$)$ & 0.91 (0.88 to 0.94$)$ & 0.97 (0.93 to 1.00$)$ \\
\hline Rural & 0.94 (0.90 to 0.98$)$ & 1.00 (0.96 to 1.05$)$ & 0.99 (0.95 to 1.04$)$ & 1.01 (0.96 to 1.06$)$ \\
\hline \multicolumn{5}{|l|}{ Income quintile } \\
\hline 1 (low) & 1.06 (1.01 to 1.11$)$ & 1.08 (1.03 to 1.14$)$ & 1.12 (1.06 to 1.18$)$ & 1.08 (1.02 to 1.14$)$ \\
\hline 2 & 1.03 (0.98 to 1.08$)$ & 1.04 (0.99 to 1.09$)$ & $1.04(0.99$ to 1.10$)$ & 1.04 (0.98 to 1.09$)$ \\
\hline 3 & $1.06(1.01$ to 1.11$)$ & 1.03 (0.98 to 1.09$)$ & 1.04 (0.98 to 1.10$)$ & 0.99 (0.94 to 1.04$)$ \\
\hline 4 & 1.02 (0.97 to 1.08$)$ & 0.99 (0.94 to 1.05$)$ & 1.08 (1.03 to 1.14$)$ & 1.01 (0.95 to 1.06$)$ \\
\hline 5 (high) & Reference & Reference & Reference & Reference \\
\hline Benign hypertension & 0.76 (0.74 to 0.79$)$ & 0.74 (0.72 to 0.77$)$ & 0.73 (0.70 to 0.76$)$ & 0.78 (0.75 to 0.81$)$ \\
\hline Complicated hypertension & $0.93(0.86$ to 1.00$)$ & 0.95 (0.88 to 1.02$)$ & 0.87 (0.82 to 0.93$)$ & 0.77 (0.73 to 0.81$)$ \\
\hline Atrial fibrillation & 0.89 (0.85 to 0.94$)$ & 0.92 (0.88 to 0.96$)$ & 0.96 (0.92 to 1.01$)$ & 0.99 (0.95 to 1.04$)$ \\
\hline Myocardial infarction & 1.12 (1.06 to 1.18$)$ & 0.99 (0.94 to 1.05$)$ & 1.02 (0.97 to 1.06$)$ & 0.98 (0.94 to 1.03$)$ \\
\hline Valvular disease & $1.00(0.92$ to 1.08$)$ & 0.98 (0.91 to 1.06$)$ & 0.97 (0.90 to 1.05$)$ & $0.93(0.86$ to 1.00$)$ \\
\hline Peripheral arterial disease & $1.22(1.16$ to 1.29$)$ & $1.2(1.14$ to 1.27$)$ & $1.28(1.20$ to 1.37$)$ & 1.34 (1.24 to 1.44$)$ \\
\hline Cerebrovascular disease & 1.29 (1.23 to 1.35$)$ & 1.25 (1.19 to 1.32$)$ & 1.23 (1.16 to 1.30$)$ & $1.20(1.13$ to 1.28$)$ \\
\hline Pulmonary circulatory disease & 1.67 (1.43 to 1.96$)$ & 1.73 (1.52 to 1.97$)$ & 1.54 (1.38 to 1.71$)$ & 1.24 (1.12 to 1.37$)$ \\
\hline COPD/asthma & 1.15 (1.12 to 1.19$)$ & 1.18 (1.14 to 1.22$)$ & $1.21(1.17$ to 1.25$)$ & $1.17(1.13$ to 1.21$)$ \\
\hline Alcohol abuse & $1.16(0.97$ to 1.38$)$ & 1.34 (1.16 to 1.55$)$ & 1.51 (1.34 to 1.70$)$ & 1.62 (1.45 to 1.82$)$ \\
\hline Renal disease & 2.04 (1.90 to 2.18$)$ & 1.86 (1.74 to 1.98$)$ & 1.73 (1.63 to 1.84$)$ & 1.67 (1.58 to 1.77$)$ \\
\hline Diabetes & 1.25 (1.21 to 1.30$)$ & 1.19 (1.15 to 1.24$)$ & 1.13 (1.09 to 1.17$)$ & $1.13(1.10$ to 1.17$)$ \\
\hline Hypothyroidism & 0.99 (0.91 to 1.07$)$ & 1.01 (0.93 to 1.09$)$ & 1.03 (0.93 to 1.13$)$ & $1.06(0.96$ to 1.17$)$ \\
\hline Liver disease & $1.90(1.72$ to 2.10$)$ & 1.86 (1.68 to 2.06$)$ & 1.99 (1.79 to 2.21$)$ & 2.34 (2.12 to 2.59 ) \\
\hline Dementia & 1.74 (1.63 to 1.85$)$ & 1.97 (1.86 to 2.09$)$ & 2.03 (1.91 to 2.16$)$ & 1.96 (1.84 to 2.09$)$ \\
\hline Depression & 1.15 (1.07 to 1.25$)$ & 1.18 (1.09 to 1.28$)$ & 1.19 (1.09 to 1.30$)$ & 1.16 (1.06 to 1.28$)$ \\
\hline Psychosis & 1.29 (1.20 to 1.38$)$ & 1.36 (1.26 to 1.46$)$ & 1.14 (0.99 to 1.31$)$ & $1.43(1.17$ to 1.76$)$ \\
\hline Primary tumour & 1.56 (1.49 to 1.64$)$ & 1.69 (1.60 to 1.77$)$ & 1.61 (1.53 to 1.70$)$ & 1.64 (1.56 to 1.73$)$ \\
\hline Metastatic malignancy & 3.47 (3.22 to 3.74$)$ & 3.59 (3.33 to 3.87 ) & 3.14 (2.90 to 3.41$)$ & 3.42 (3.17 to 3.70$)$ \\
\hline Paraplegia & 1.36 (1.24 to 1.50$)$ & 1.33 (1.21 to 1.46$)$ & $1.52(1.35$ to 1.70$)$ & $1.53(1.35$ to 1.75$)$ \\
\hline Venous thromboemoblism & 1.07 (0.98 to 1.17$)$ & 1.18 (1.07 to 1.30$)$ & 1.16 (1.03 to 1.31$)$ & 1.40 (1.24 to 1.58$)$ \\
\hline
\end{tabular}

Risk factors that have changed in magnitude between the historical (1994-1998) and modern (2009-2013) times are indicated in bold. COPD, chronic obstructive pulmonary disease.

demonstrated that the protective effect conferred by female sex had diminished over time (adjusted HR 0.85, $95 \%$ CI 0.82 to 0.88 in the historical and $0.97,95 \%$ CI 0.93 to 1.00 in the modern cohort).

Table 2 lists the multivariable predictors of 1-year mortality in the modern cohort. Compared with the historical cohort, the mortality risk associated with age $>75$ years, liver disease, dementia and venous thromboembolism had increased while the risk associated with male sex, complicated hypertension, diabetes, renal disease and pulmonary circulatory disease had diminished. Of note, alcohol abuse and venous thromboembolism emerged as new mortality risk factors while urban residence and MI were no longer risk factors.

Sex-specific mortality risk factors have evolved over time. Tables 3 and 4 illustrate the sex-specific HRs in the historical and modern cohorts, respectively. In the modern cohort, low income was associated with a higher 
Table 3 Sex-specific risk factors of 1-year mortality in the historical cohort (1994-1998)

\begin{tabular}{|c|c|c|c|}
\hline Variable & Women & Men & Multiplicative interaction \\
\hline & $\mathrm{HR}(95 \% \mathrm{Cl})$ & $\mathrm{HR}(95 \% \mathrm{Cl})$ & $P$ value* \\
\hline \multicolumn{4}{|l|}{ Age category } \\
\hline $65-74$ years & 1.45 (1.32 to 1.59$)$ & 1.63 (1.51 to 1.75$)$ & \\
\hline 75-84 years & 2.06 (1.89 to 2.24$)$ & 2.42 (2.25 to 2.60$)$ & \\
\hline Benign hypertension & 0.70 (0.67 to 0.73$)$ & 0.82 (0.79 to 0.86$)$ & $<0.001$ \\
\hline Myocardial infarction & 1.26 (1.16 to 1.36$)$ & 1.02 (0.95 to 1.10$)$ & $<0.001$ \\
\hline COPD/asthma & 1.10 (1.05 to 1.16$)$ & 1.20 (1.15 to 1.25$)$ & 0.01 \\
\hline Renal disease & 2.26 (2.04 to 2.50$)$ & 1.90 (1.74 to 2.07$)$ & 0.01 \\
\hline Diabetes & 1.31 (1.25 to 1.38$)$ & 1.20 (1.14 to 1.26$)$ & 0.01 \\
\hline
\end{tabular}

*Multiplicative interaction terms were formed by multiplying sex by each of the covariates in the multivariable Cox proportional hazard model for 1-year mortality. Only significant interaction terms (ie, ones demonstrating sex-specific risk factors) were reported in this table.

COPD, chronic obstructive pulmonary disease.

risk of mortality in men but not in women. Conversely, MI had a mild protective effect on men but not in women. In addition, women with peripheral arterial disease had a higher risk of death while men with COPD/asthma, dementia, primary and metastatic malignancies had a higher risk of mortality than women with similar comorbidities. Compared with the historical cohort, most sexspecific risk factors have evolved over time, with the exception of COPD/asthma.

\section{Trends in HF hospitalisation}

HF hospitalisations occurred in 5271 (13.4\%) women and $5169(14.4 \%)$ men within 1 year of HF diagnosis in the historical cohort. During the modern period, there were $5420(15.6 \%)$ HF hospitalisations in women and $5503(13.8 \%)$ hospitalisations in men. Age-standardised HF hospitalisation rates declined in men (linear regression slope, $-0.010 ; \mathrm{p}=0.0002$ ) but remained unchanged in women (linear regression slope, $-0.005 ; \mathrm{p}=0.11$ ) during the 20-year period (online supplemental figure 1 and table 4). Specifically, male age-standardised HF hospitalisation rates were $11.4 \%$ (95\% CI $10.1 \%$ to $12.9 \%$ ) in 1994 and $9.1 \%$ (95\% CI $8.2 \%$ to $10.1 \%$ ) in 2013 . Female rates were $9.7 \%$ (95\% CI $8.3 \%$ to $11.3 \%$ ) in 1994 and $9.8 \%$ (95\% CI $8.6 \%$ to $11.0 \%$ ) in 2013.The temporal trends in the cumulative incidence of HF hospitalisations are illustrated in (online supplemental figure 2).

Table 4 Sex-specific risk factors of 1-year mortality in the modern cohort (2009-2013)

\begin{tabular}{llll}
\hline Variable & Women & Men & Multiplicative interaction \\
\hline & $\mathrm{HR}(95 \% \mathrm{Cl})$ & $\mathrm{HR}(95 \% \mathrm{Cl})$ & $\mathrm{P}$ value* \\
\hline Income quintile & & & \\
\hline 1 (low) & $1.02(0.94$ to 1.09$)$ & $1.15(1.06$ to 1.23$)$ & 0.001 \\
\hline 2 & $0.97(0.90$ to 1.05$)$ & $1.10(1.02$ to 1.18$)$ & \\
\hline 3 & $0.99(0.92$ to 1.07$)$ & $0.98(0.91$ to 1.06$)$ & \\
\hline 4 & $1.01(0.93$ to 1.09$)$ & $1.01(0.93$ to 1.08$)$ & \\
\hline 5 (high) & Reference & Reference & 0.02 \\
\hline Myocardial infarction & $1.05(0.98$ to 1.12$)$ & $0.94(0.89$ to 1.00$)$ & 0.02 \\
\hline Peripheral arterial disease & $1.48(1.32$ to 1.66$)$ & $1.25(1.14$ to 1.37$)$ & 0.05 \\
COPD/asthma & $1.12(1.07$ to 1.17$)$ & $1.23(1.17$ to 1.29$)$ & $<0.001$ \\
Dementia & $1.87(1.72$ to 2.02$)$ & $2.10(1.92$ to 2.30$)$ & $<0.001$ \\
\hline Primary tumour & $1.44(1.34$ to 1.56$)$ & $1.79(1.68$ to 1.91$)$ & \\
\hline Metastatic malignancy & $3.05(2.75$ to 3.38$)$ & $3.85(3.49$ to 4.26$)$ &
\end{tabular}

ed in this table.

*Multiplicative interaction terms were formed by multiplying sex by each of the covariates in the multivariable Cox proportional hazard model for 1-year mortality. Only significant interaction terms (ie, ones demonstrating sex-specific risk factors) were reported in this table.

COPD, chronic obstructive pulmonary disease. 


\section{DISCUSSION}

This population-based study evaluated 352329 individuals with a first-time diagnosis of HF from 1994 to 2013 in the ambulatory care setting. There are four main findings reported in this study: (1) HF mortality declined over time, (2) The reduction in mortality is greater in men than in women, (3) Rates of hospitalisation decreased for men but remained unchanged for women and (4) The incidence and significance of comorbidities associated with HF have changed over time, and suggest that women continue to experience a greater burden of comorbid disease when compared with men.

\section{Trends in HF incidence and mortality}

Population-based temporal trends in HF incidence and mortality have been previously reported across many cohorts, however, many of these studies have been limited to patients hospitalised with a diagnosis of HF or have not provided detailed, sex-stratified analyses. Temporal trends in the incidence and survival of HF patients were first reported by the Framingham group over a 50 year period from 1950 to $1999 .{ }^{35}$ These authors reported that the incidence of $\mathrm{HF}$ had declined in women but not men, with improving survival in both sexes. ${ }^{35}$ This pivotal study was followed by findings from a community-based cohort of 4537 patients from 1979 to 2000 , which reported that although HF incidence remained unchanged for both sexes, mortality declinedwith greater survival gains in men than women. ${ }^{36} \mathrm{~A}$ recent study by our group demonstrated that among ambulatory Ontario residents from 2009 to 2013, the incidence of HF decreased more rapidly in men than women. At the same time, HF associated deaths and hospitalisations remain higher in women than men within a year of HF diagnosis. ${ }^{19}$ The present study extends these findings by demonstrating a continued disproportionate decrease in HF mortality for men compared with women from 1994 to 2013. Our findings corroborate with our previous study of $\mathrm{HF}$ incidence and 1-year mortality in rural and urban Eastern Ontario from 1994 to $2013 .{ }^{24}$ They also corroborate the work of Tu et al $l^{7}$ who used similar administrative databases to report on the HF incidence and mortality of Ontario patients $\geq 20$ years of age from 1997 to 2007. Tu et al evaluated both admitted and ambulatory HF patients and reported declines in HF incidence over this time period, a finding that was most evident in the older cohorts. ${ }^{7}$ Sex stratified mortality rates were not reported in this study. A recent study from Denmark demonstrated a decrease in HF incidence over time only in cohorts $>50$ years of age, but an increase in HF incidence in younger patients. Although detailed sex-specific outcomes were not provided, sex-stratified models showed similar trends in incidence and mortality over time with men having a higher incidence overall. ${ }^{8}$

The present study extends these observations by providing detailed sex-specific data on mortality trends over time. Our findings suggest that in Ontario, 1-year mortality rates have decreased over the past 20 years. However, this mortality reduction was greatest for men, and observed to a lesser extent for women. This translates to the observation that women had better AMR than men in the first three temporal cohorts of this study (19942008); however, in the most recent cohort (2009-2013) we observed mortality to be higher in women than men for the first time. The basis for this sex-based difference is unclear but may be explained in part by the observation that women are more likely than men to have a diagnosis of $\mathrm{HF}$ with preserved ejection fraction (HFpEF), a disease for which there remains no evidence-based therapies which can improve survival, in contrast to the significant advances in medical therapy for HF with reduced ejection fraction (HFrEF) ${ }^{37}$ In addition, female patients with HF have a higher comorbidity burden than their male counterparts. Complex comorbid conditions, coupled with atypical presentation of cardiac disease in women, may also have lead to delays in diagnosis and differences in management or response to medical therapy. ${ }^{38}$ Further work is needed to determine whether the other sex-based differences in management, response to treatment or underlying pathophysiology remain to explain these sexbased trends in HF mortality over time.

\section{Trends in HF hospitalisation}

Rates of hospitalisation for HF decreased only for men in this time period. This is consistent with recent reports of sex and race differences in hospitalisation trends over a similar time period. ${ }^{19}{ }^{39}$ It is possible that this sex-based difference may be due to death being a competing risk for hospitalisation in men, such that men with HF may suffer earlier deaths whereas women with HF survive to an older age and are more likely to become hospitalised. Alternatively, it is possible that the rates of hospitalisation in men and women reflect the underlying HF type, since men are more likely to have HFrEF (for which there are several treatments known to improve outcomes and decrease hospitalisation) while women are more likely to have HFpEF (for which there are no substantial evidencebased therapies). Nonetheless, the observed sex differences may also be attributed to the greater comorbidity burden in women, differences in social determinants of health or genetic or physiological differences that cannot be explained within the observational context of this study; all of these point to the need for further exploration to determine the adverse trends for mortality and hospitalisation in women with a diagnosis of HF.

\section{Trends in HF comorbidities}

Sex-based differences in comorbidities have been previously reported in hospitalised patients; women with HF are older and more likely than men to have comorbid hypertension, renal failure, obesity and depression. Men with $\mathrm{HF}$ are more often smokers, and tend to have more ischaemic heart disease, COPD and HFrEF. ${ }^{40}$ Our study is the first to report on the relationship between sex and comorbidity in ambulatory HF patients over time. Compared with our historical cohort, our most recent cohort of patients demonstrates an overall increase in important comorbidities such as frailty, diabetes, renal 
disease, MI, atrial fibrillation, COPD and hypertension. This has been observed in other population-based studies $^{8}$ and speaks to the increased complexity of the patient with HF in the current era. The increased prevalence of these comorbidities over time was seen in both women and men. Certain comorbidities remained more common in women than in men in both the historical and recent cohorts; including depression, hypertension, advanced age, frailty, dementia and thyroid disease. Interestingly, frailty, chronic pulmonary disease, and metastatic cancer became more common in women than men in the recent cohort. Collectively these findings suggest that the comorbidity of the HF patient is increasing over time, and that women continue to experience a greater comorbidity burden than men. This observation may also explain in part the sex difference in mortality trends.

Important trends in the risk associated with these comorbidities were also observed. Hypertension conferred a greater protective effect in the modern era. This may actually reflect the known adverse prognosis associated with low blood pressure in $\mathrm{HF}^{41}{ }^{42}$ In addition, the risk associated with diabetes, renal disease and pulmonary circulatory disease has decreased over time. In addition, MI was no longer a mortality risk factor in the recent cohort when compared with the historical cohort. These changes over time may be due to significant advances in the medical management of these comorbidities, which have influenced overall survival.

Sex-based differences in the risks associated with certain comorbidities were also observed. In the most recent cohort, MI had a mild protective effect in men but not in women. This may be due to a lower detection rate of ischaemic heart disease in women due to atypical presentation, ${ }^{43}$ which leads to missed management and poorer outcomes. Ischaemic heart disease is a leading cause of HF in both sexes. When diagnosed with ischaemic heart disease, women are less likely than men to undergo cardiac catheterisation and revascularisation; whether this is wholly attributed to the increased microvascular disease in women is not well understood. ${ }^{44}$ In the most recent cohort, peripheral arterial disease was associated with a higher risk of mortality in women, while COPD, dementia and malignancy posed a greater risk of mortality in men. Whether these differences are clinically relevant, or help to explain the variability in mortality risk associated with HF, remains to be determined. There remains a significant knowledge gap on sex specific differences in epidemiology, pathophysiology, management and prognosis of comorbidities related to $\mathrm{HF}^{40}$ Such knowledge could determine if HF management should be targeted to specific sex-based comorbidities to improve outcomes and narrow the gap in mortality improvement between women and men.

\section{Limitations and strengths}

Our study has several limitations. First, cases of HF were identified in the ambulatory care setting based on the requirement of two claims for $\mathrm{HF}$ within 1 year. Although this method may have led to an underestimate of HF, it has been validated previously and shown to improve the specificity of our case selection. ${ }^{79}$ Second, our algorithm for ascertainment of $\mathrm{HF}$ is validated in patients who are 40 years of age and older, thus limiting the generalisability of our findings. Third, information on ejection fraction was not available in the databases used, which precluded analyses in subtypes of HF based on ventricular function. Fourth, the diagnostic criteria for HFpEF have become more specific over time; whether this may influence incidence and prognosis cannot be determined from this study. Finally, cohort studies are by nature subjected to residual confounding. Despite these limitations, our study is the first to address the epidemiology of $\mathrm{HF}$ in a validated cohort of ambulatory patients, and one of the first to report on detailed sex-based outcome and comorbidity differences within a large universal healthcare system, using the same entry criteria over a 20-year time period. The nature of our publicly funded healthcare system allowed for complete analysis of all Ontario HF patients, which minimised selection bias and greatly improved the generalisability of our findings.

\section{CONCLUSIONS}

Over a 20-year window, we found an overall reduction in all-cause mortality in the year following HF diagnosis. However, there was a much larger reduction of mortality in men than in women, and HF hospitalisation rates have decreased for men but remained unchanged in women. Specifically, mortality and hospitalisation rates were higher in men than women at the start of the study period and were similar between sexes towards the end of this period. Female patients with HF continue to experience a greater burden of comorbidities than male patients with HF in the modern era. Further research should focus on the determinants of this disparity such as sex differences in medical and device management, to better characterise incidence and outcomes by HF type, and ways to reduce this gap in outcomes.

\section{Author affiliations}

${ }^{1}$ Division of Cardiac Anesthesiology, Department of Anesthesiology and Pain Medicine, University of Ottawa Heart Institute, Ottawa, Ontario, Canada

${ }^{2}$ Cardiovasulcar Research Program, ICES (formerly the Institute for Clinical Evaluative Sciences), Toronto, Ontario, Canada

${ }^{3}$ School of Epidemiology and Public Health, University of Ottawa, Ottawa, Ontario, Canada

${ }^{4}$ Division of Cardiology, Department of Medicine, University of Ottawa Heart Institute, Ottawa, Ontario, Canada

${ }^{5}$ Division of Prevention and Rehabilitation, University of Ottawa Heart Institute, Ottawa, Ontario, Canada

${ }^{6}$ Peter Munk Cardiac Centre, University Health Network, University of Toronto,

Toronto, Ontario, Canada

${ }^{7}$ Sunnybrook Schulich Heart Centre, University of Toronto, Toronto, Ontario, Canada

\section{Twitter Louise Y Sun @sunlouise1}

Acknowledgements This article is dedicated to the memory Jack V. Tu, MD, PhD, who was a mentor and friend to LYS, DSL and PCA and a respected colleague to all. The authors are indebted to his contributions to this manuscript. This study was supported by the Institute for Clinical Evaluative Sciences (ICES), which is funded by 
an annual grant from the Ontario Ministry of Health and Long-Term Care (MOHLTC). The authors acknowledge the usage of data compiled and provided by the Canadian Institute for Health Information. These datasets were linked using unique encoded identifiers and analyzed at ICES. The analyses, conclusions, opinions and statements expressed in the manuscript are those of the authors, and do not necessarily reflect those of the above agencies.

Contributors Conception: LYS and LMM. Design: LYS, LMM and JVT. Data acquisition and analysis: LYS and ABE. Interpretation of results: LYS, LMM, PPL, RSB, SC, RD, TC, DSL, PCA, ABE and JVT. Drafting of manuscript: LYS, LMM. Critical revision: LYS, LMM, PPL, RSB, SC, RD, TC, DSL, PCA, ABE and JVT. Agreement to be accountable for all aspects of the work: LYS.

Funding This work was supported by a Team grant from the University of Ottawa Heart Institute (UOHI) (Grant \#4556) Ontario, Canada. LYS was named National New Investigator by the Heart and Stroke Foundation of Canada and is supported by a Tier 2 Clinical Research Chair in Big Data and Cardiovascular Outcomes at the University of Ottawa. LMM holds a University of Ottawa Tier 1 Chair in Heart Failure Research and is supported as a Clinician Scientist from the Heart and Stroke Foundation of Ontario (HSFO). PCA and RSB hold Career Investigator Awards from the HSFO. RSB holds a University of Ottawa Tier 1 Chair in Cardiac Imaging Research; and is the UOHI Vered Chair in Cardiology. JVT was supported by a Canada Research Chair in Health Services Research and an Eaton Scholar Award from the Department of Medicine, University of Toronto, Ontario, Canada.

Disclaimer The funders do not have a role in the design and conduct of the study, in the collection, analysis, and interpretation of the data, nor in the preparation, review, or approval of the manuscript.

Competing interests None declared.

Patient consent for publication Not required.

Ethics approval The Research Ethics Board of Sunnybrook Health Sciences, Toronto, Canada approved this study and waived the need for informed consent.

Provenance and peer review Not commissioned; externally peer reviewed.

Data availability statement The dataset from this study is held securely in coded form at ICES (formerly the Institute for Clinical Evaluative Sciences).

Supplemental material This content has been supplied by the author(s). It has not been vetted by BMJ Publishing Group Limited (BMJ) and may not have been peer-reviewed. Any opinions or recommendations discussed are solely those of the author(s) and are not endorsed by BMJ. BMJ disclaims all liability and responsibility arising from any reliance placed on the content. Where the content includes any translated material, BMJ does not warrant the accuracy and reliability of the translations (including but not limited to local regulations, clinical guidelines, terminology, drug names and drug dosages), and is not responsible for any error and/or omissions arising from translation and adaptation or otherwise.

Open access This is an open access article distributed in accordance with the Creative Commons Attribution Non Commercial (CC BY-NC 4.0) license, which permits others to distribute, remix, adapt, build upon this work non-commercially, and license their derivative works on different terms, provided the original work is properly cited, appropriate credit is given, any changes made indicated, and the use is non-commercial. See: http://creativecommons.org/licenses/by-nc/4.0/.

\section{ORCID iD}

Louise Y Sun http://orcid.org/0000-0003-3381-3115

\section{REFERENCES}

1 McMurray JJV, Adamopoulos S, Anker SD, et al. Esc guidelines for the diagnosis and treatment of acute and chronic heart failure 2012: the task force for the diagnosis and treatment of acute and chronic heart failure 2012 of the European Society of cardiology. developed in collaboration with the heart failure association (HFA) of the ESC. Eur Heart J 2012;33:1787-847.

2 Huffman MD, Berry JD, Ning $\mathrm{H}$, et al. Lifetime risk for heart failure among white and black Americans: cardiovascular lifetime risk pooling project. J Am Coll Cardiol 2013;61:1510-7.

3 Roger VL, Go AS, Lloyd-Jones DM, et al. Heart disease and stroke statistics--2011 update: a report from the American Heart Association. Circulation 2011;123:e18-209.

4 Norberg $\mathrm{H}$. Clinical trial enrolment favours men: fewer women meet eligibility criteria for trials of heart failure medication is discussed by Helena Norberg from Sweden. Eur Heart J 2019;40:1104-5.
5 Scantlebury DC, Borlaug BA. Why are women more likely than men to develop heart failure with preserved ejection fraction? Curr Opin Cardiol 2011;26:562-8.

6 Kenchaiah S, Vasan RS. Heart Failure in Women--Insights from the Framingham Heart Study. Cardiovasc Drugs Ther 2015;29:377-90.

7 Yeung DF, Boom NK, Guo H, et al. Trends in the incidence and outcomes of heart failure in Ontario, Canada: 1997 to 2007. Can Med Assoc J 2012;184:E765-73.

8 Christiansen MN, Køber L, Weeke P, et al. Age-Specific trends in incidence, mortality, and comorbidities of heart failure in Denmark 1995 to 2012. Circulation 2017;135:1214-23.

9 Schultz SE, Rothwell DM, Chen Z, et al. Identifying cases of congestive heart failure from administrative data: a validation study using primary care patient records. Chronic Dis Inj Can 2013;33:160-6.

10 Tu K, Campbell NR, Chen Z-L, et al. Accuracy of administrative databases in identifying patients with hypertension. Open Med 2007;1:e18-26.

11 Juurlink D, Preya C, Croxford R, et al. Canadian Institute for Health Information Discharge Abstract Database: A Validation Study. ICES Investigative Report. Toronto, ON: Institute for Clinical Evaluative Sciences, 2006.

12 Hux JE, Ivis F, Flintoft V, et al. Diabetes in Ontario: determination of prevalence and incidence using a validated administrative data algorithm. Diabetes Care 2002;25:512-6.

13 Austin PC, Daly PA, Tu JV. A multicenter study of the coding accuracy of hospital discharge administrative data for patients admitted to cardiac care units in Ontario. Am Heart $J$ 2002;144:290-6.

14 Plessis du V, Beshiri R, Bollman RD, et al. Agriculture and Rural Working Paper Series, No. 61. Ottawa, ON: Statistics Canada, 2002.

15 Gershon AS, Wang C, Guan J, et al. Identifying patients with physician-diagnosed asthma in health administrative databases. Can Respir J 2009;16:183-8.

16 Gershon AS, Wang C, Guan J, et al. Identifying individuals with physcian diagnosed COPD in health administrative databases. COPD 2009;6:388-94.

17 Quan H, Sundararajan V, Halfon P, et al. Coding algorithms for defining comorbidities in ICD-9-CM and ICD-10 administrative data. Med Care 2005;43:1130-9.

18 Sun LY, Gershon AS, Ko DT, et al. Trends in pulmonary function testing before Noncardiothoracic surgery. JAMA Intern Med 2015; 175:1410-2.

19 Sun LY, JV T, Coutinho T, et al. Sex differences in heart failure outcomes in an ambulatory, population-based cohort. CMAJ 2018;190:E848-54.

20 Sun LY, Tu JV, Lee DS, et al. Disability-free survival after coronary artery bypass grafting in women and men with heart failure. Open Heart 2018;5:e000911.

21 Sun LY, Gaudino M, Chen RJ, et al. Long-Term outcomes in patients with severely reduced left ventricular ejection fraction undergoing percutaneous coronary intervention vs coronary artery bypass grafting. JAMA Cardiol 2020;5:631.

22 Sun LY, Kimmoun A, Takagi K, et al. Ethnic differences in acute heart failure outcomes in Ontario. Int J Cardiol 2019;291:177-82.

23 Sun LY, Tu JV, Bader Eddeen A, et al. Prevalence and Long-Term survival after coronary artery bypass grafting in women and men with heart failure and preserved versus reduced ejection fraction. J Am Heart Assoc 2018;7:1-14.

24 Sun LY, Tu JV, Sherrard H, et al. Sex-Specific trends in incidence and mortality for urban and rural ambulatory patients with heart failure in eastern Ontario from 1994 to 2013. J Card Fail 2018;24:568-74

25 Tran DTT, Tu JV, Dupuis J-Y, Dupuis Jean-Yves, et al. Association of frailty and long-term survival in patients undergoing coronary artery bypass grafting. J Am Heart Assoc 2018;7. doi:10.1161/ JAHA.118.009882. [Epub ahead of print: 2007 2018].

26 Johnston A, Mesana TG, Lee DS, et al. Sex differences in long-term survival after major cardiac surgery: a population-based cohort study. J Am Heart Assoc 2019;8:e013260.

27 Hayatsu Y, Ruel M, Bader Eddeen A, et al. Single versus multiple arterial revascularization in patients with reduced renal function: long-term outcome comparisons in 23,406 CABG patients from Ontario, Canada. Ann Surg 2020.

28 Sun LY, Spence SD, Benton S, et al. Age, not sex, modifies the effect of frailty on long-term outcomes after cardiac surgery. Ann Surg 2020; Publish Ahead of Print.

29 Rubens FD, Wells GA, Coutinho T, et al. Sex differences after coronary artery bypass grafting with a second arterial conduit. $J$ Thorac Cardiovasc Surg 2020. doi:10.1016/j.jtcvs.2020.04.058. [Epub ahead of print: 23 Apr 2020]. 
30 Lieberman RAC, Weiner J. Development and evaluation of the Johns Hopkins University risk adjustment models for Medicare+ choice plan payment, 2003.

31 Sternberg SA, Bentur N, Abrams C, et al. Identifying frail older people using predictive modeling. Am J Manag Care 2012;18:e392-7.

32 The Johns Hopkins Adjusted Clinical Groups Technical Reference Guide, version 9.0. 2009.

33 Bronskill SCM, Costa A. Aging in Ontario: An ICES Chartbook of Health Services Use by Older Adults - a Technical Report; 2010.

34 Bronskill SCX, Gruneir A, Ho M. Health system use by frail Ontario seniors: an in-depth examination of four vulnerable cohorts, 2011.

35 Levy D, Kenchaiah S, Larson MG, et al. Long-Term trends in the incidence of and survival with heart failure. $N$ Engl J Med 2002;347:1397-402.

36 Roger VL, Weston SA, Redfield MM, et al. Trends in heart failure incidence and survival in a community-based population. JAMA 2004;292:344-50.

37 Yancy CW, Jessup M, et al, WRITING COMMITTEE MEMBERS. 2016 ACC/AHA/HFSA focused update on new pharmacological therapy for heart failure: an update of the 2013 ACCF/AHA guideline for the management of heart failure: a report of the American College of Cardiology/American heart association Task force on clinical practice guidelines and the heart failure Society of America. Circulation 2016;134:e282-93

38 Taylor AL. Heart failure in women. Curr Heart Fail Rep 2015;12:187-95.

39 Ziaeian B, Kominski GF, Ong MK, et al. National differences in trends for heart failure hospitalizations by sex and Race/Ethnicity. Circ Cardiovasc Qual Outcomes 2017;10.

40 Hopper I, Kotecha D, Chin KL, et al. Comorbidities in heart failure: are there gender differences? Curr Heart Fail Rep 2016;13:1-12.

41 Raphael CE, Whinnett ZI, Davies JE, et al. Quantifying the paradoxical effect of higher systolic blood pressure on mortality in chronic heart failure. Heart 2009;95:56-62.

42 Schmid FA, Schlager O, Keller P, et al. Prognostic value of long-term blood pressure changes in patients with chronic heart failure. Eur $J$ Heart Fail 2017;19:837-42.

43 Jarvie JL, Foody JM. Recognizing and improving health care disparities in the prevention of cardiovascular disease in women. Curr Cardiol Rep 2010;12:488-96.

44 McSweeney J, Pettey C, Lefler LL, et al. Disparities in heart failure and other cardiovascular diseases among women. Womens Health 2012;8:473-85. 